\title{
Hand grip strength is associated with fatigue in COPD
}

\section{Viktor Johansson Strandkvist, PT, MSc',2, Helena Backman, PhD², Mikael Andersson ${ }^{3}$, PT, PhD, Agneta Larsson', PT, PhD, Caroline Stridsman4, RN, PhD, Anne Lindberg ${ }^{5}$, MD, PhD}

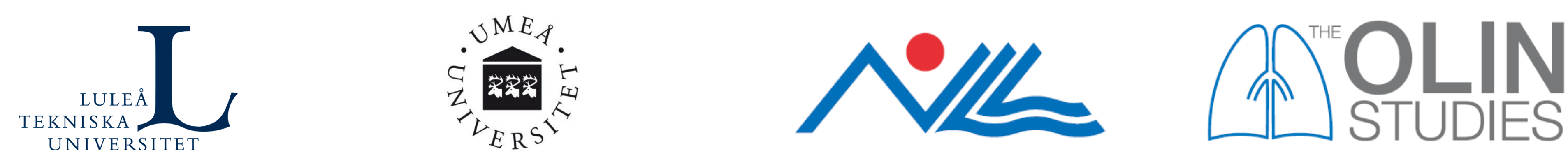

\section{Background}

Hand grip strength $(\mathrm{HGS})^{1}$ and fatigue ${ }^{2}$ are both related to the burden of disease in COPD, but the relationship between HGS and fatigue among subjects with COPD is unknown.

\section{Aims}

To evaluate the relationship between HGS and fatigue among subjects with and without COPD in a population based study.

\section{Methods}

A COPD sample has, together with age- and sex-matched referents withou COPD, been followed annually since 2005 in the OLIN COPD study. In 2014 304 subjects with and 362 subjects without COPD were clinically examined including interviews, spirometry, HGS and the FACIT-Fatigue questionnaire (0-52, lower scores represent increased fatigue). HGS was measured by a hand held dynamometer, Jamar ${ }^{\circledR 3}$. Clinically relevant fatigue (CRF) was defined as FACIT-Fatigue score $\leq 43$. COPD was defined as postbronchodilator FEV $/ \mathrm{VC}<0.70$, and assessment of disease severity was basedO OLIN reference values for $\mathrm{FEV}^{4}$. All analyses were stratified by sex.

Table 1. Study population, basic characteristics, comparing non-COPD and COPD among women and men, respectively.

\begin{tabular}{|c|c|c|c|c|c|c|}
\hline & \multicolumn{3}{|c|}{ Women } & \multicolumn{3}{|c|}{ Men } \\
\hline & $\begin{array}{c}\text { Non- } \\
\text { COPD } \\
n=198\end{array}$ & $\begin{array}{l}\text { COPD } \\
n=164\end{array}$ & $p$-value & $\begin{array}{c}\text { Non-COPD } \\
n=239\end{array}$ & $\begin{array}{l}\text { COPD } \\
n=217\end{array}$ & $\mathrm{p}$-value \\
\hline Age, mean (SD) & $70.3(9.8)$ & $72.8(8.7)$ & 0.011 & $70.1(9.0)$ & $71.6(9.0)$ & 0.083 \\
\hline Smoker, n (\%) & $17(8.6)$ & $29(17.7)$ & & $10(4.2)$ & $45(20.5)$ & \\
\hline Ex smoker, n (\%) & $71(35.9)$ & $75(45.7)$ & & $122(51.0)$ & $116(53.5)$ & \\
\hline Non smoker, n (\%) & $110(55.6)$ & $60(36.6)$ & $<0.001$ & $107(44.8)$ & $56(25.8)$ & $<0.001$ \\
\hline Height, mean (SD) & $160.3(6.7)$ & $159.8(6.6)$ & 0.460 & $173.8(7.1)$ & $174.3(6.7)$ & 0.425 \\
\hline $\mathrm{BMI}, \mathrm{kg} / \mathrm{m} 2$, mean (SD) & $27.8(4.73)$ & 26.6 (4.6) & 0.015 & $27.4(3.7)$ & $26.9(4.0)$ & 0.111 \\
\hline $\mathrm{FEV}_{1} \%$ pred, mean (SD) & $99.4(14.0)$ & $81.2(15.9)$ & $<0.001$ & $95.1(13.4)$ & $76.5(17.5)$ & $<0.001$ \\
\hline Respiratory symptoms', n(\%) & $77(38.9)$ & $97(59.1)$ & $<0.001$ & $105(44.9)$ & $147(67.7)$ & $<0.001$ \\
\hline Heart disease 2 , n (\%) & $18(9.1)$ & $21(12.8)$ & 0.225 & $46(19.2)$ & $51(23.5)$ & 0.296 \\
\hline HGS, mean (SD) & $24.6(6.8)$ & $22.8(5.5)$ & 0.008 & $43.3(9.6)$ & $41.1(9.5)$ & 0.013 \\
\hline
\end{tabular}
IRespiratory symptoms: self-reported history of at least one of; modified Medical Research Council dyspnea scale 22 ,
chronic cough, chronic productive cough or recurrent wheeze. 'Heart disease: self-reported history of at least one of; angin pectoris, myocardial infarction, cardiac insuffficiency, coronary artery bypass or Percutaneous Coronary Intervention
procedure.
Abbreviations: BMI, Body Mass Index; HGS, Hand grip strength; FEV ${ }_{1} \%$ pred, Forced expiratory volume in one second
percent of predicted; SD. Standard deviation

\section{Conclusions}

Hand grip strength was associated with fatigue among subjects with, but not without COPD.

Among men with COPD, the association between hand grip strength and fatigue remained significant also when adjusted for confounders.

Table 2. Comparing mean HGS (SD) among individuals with and without clinically relevant fatigue (CRF) in COPD and non-COPD, among women and men, respectively.

\begin{tabular}{|c|c|c|c|}
\hline \multirow{3}{*}{ Women } & \multirow[b]{2}{*}{$\begin{array}{c}\text { Non-COPD } \\
n=194\end{array}$} & \\
\hline & & $\begin{array}{l}\text { COPD } \\
n=152\end{array}$ & $p$-value \\
\hline & Mean HGS (SD) & Mean HGS (SD) & \\
\hline Non-CRF & $25.1(6.5)$ & $23.7(5.0)$ & 0.054 \\
\hline CRF & $23.2(7.2)$ & $21.9(5.9)$ & 0.323 \\
\hline$p$-value & $0.069^{\mathrm{b}}$ & $0.051^{\circ}$ & \\
\hline \multirow{2}{*}{ Men } & $n=230$ & $n=209$ & \\
\hline & Mean HGS (SD) & Mean HGS (SD) & \\
\hline Non-CRF & $44.2(9.5)$ & $43.1(8.7)$ & 0.313 \\
\hline CRF & $42.0(9.2)$ & $38.6(9.7)$ & 0.035 \\
\hline$p$-value & $0.114^{b}$ & $0.001^{c}$ & \\
\hline
\end{tabular}

"Comparing mean HGS between non-COPD and COPD. bComparing mean HGS between non-CRF and CRF in non-COP "Comparing mean HGS between non-CRF and CRF in COPD. Including all individuals with complete data on HGS and

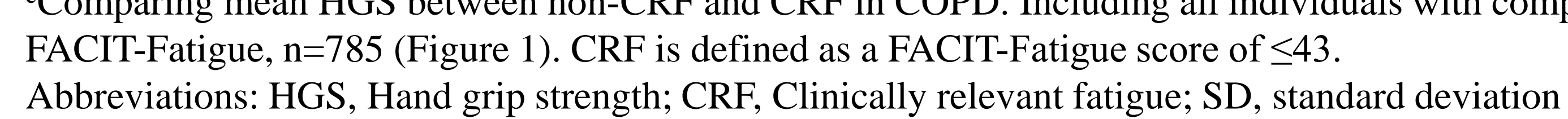
W

\section{Viktor Johansson Strandkvist, PT.}

Luleå University of Technology, Sweden, Department of Health Sciences, Division of Health and Rehabilitation 97187 Lulea The OLIN Studies Norrbotten County Council E-mail: viktor.johansson.strandkvist@ltu.se

References

'Eisner et al. Am J Med $2008^{2}$ Stridsman et al. COPD 2013

${ }^{3}$ Mathiowetz et al. J Hand Surg 1984.4 Backman et al. Eur Clin Respir J 2015

\section{Results}

Basic characteristics of the study population are shown in Table 1. Among individuals with COPD those with CRF had lower mean HGS than those without CRF, significantly so among men and close to among women (Table 2). HGS was non-significantly higher among those with compared to those without CRF in nonCOPD

Among individuals with COPD, HGS remained associated with fatigue among men, but not among women, when adjusted for age, height and smoking habits (Table 3). HGS was associated with fatigue, both when assessed as a continuou FACIT-fatigue score as well as when assessed as CRF. The corresponding analyses among subjects without COPD yielded no significant results.

Table 3. Multiple linear regression model analyzing the association between HGS and fatigue, assessed both as a continuous FACIT-fatigue score and as clinically relevant atigue (CRF, don as FACIT-Fatigue $\leq 43)$ among subjects with and without COPD, nalyses stratified for sex.

\begin{tabular}{|c|c|c|c|c|c|c|}
\hline \multirow[t]{2}{*}{ Women } & \multicolumn{3}{|c|}{$\begin{array}{c}\text { Non-COPD } \\
n=194\end{array}$} & \multicolumn{3}{|c|}{$\begin{array}{l}\text { COPD } \\
n=152\end{array}$} \\
\hline & B & \multicolumn{2}{|c|}{$95 \% \mathrm{Cl}$} & B & \multicolumn{2}{|c|}{$95 \% \mathrm{Cl}$} \\
\hline FACIT-fatigue score & 0.062 & -0.048 & 0.172 & 0.085 & -0.001 & 0.171 \\
\hline CRF & -0.961 & $-2-767$ & 0.845 & -0.924 & -2.557 & 0.708 \\
\hline \multirow[t]{2}{*}{ Men } & \multicolumn{3}{|c|}{$n=230$} & \multicolumn{3}{|c|}{$n=209$} \\
\hline & $B$ & \multicolumn{2}{|c|}{$95 \% \mathrm{Cl}$} & $B$ & \multicolumn{2}{|c|}{$95 \% \mathrm{Cl}$} \\
\hline FACIT-fatigue score & 0.115 & -0.019 & 0.250 & 0.249 & 0.131 & 0.367 \\
\hline CRF & -0.944 & -3.086 & 1.198 & -2.658 & -4.612 & -0.703 \\
\hline
\end{tabular}

All analyzes are adjusted for age, smoking habits and height. CRR is defined as a FACIT-Fatigue score of $\leq 43$.
Abbreviations: B, Beta coefficient; $H G S$, Hand Grip Strength; $\mathrm{R} F$, Clinically relevant fatigue

Acknowledgements/funding The authors thank Professor Bo Lundbäck, the initiator and scientific advisor of the OLIN studies, and
Professor Eva Rönmark, the present head of the OLIN studies for their support. Ann-Christine Jonsson and Sigrid Sundberg are acknowledged for data collection. The authors also thank Ola Bernhoff for work with Swedish Heart and Lung Association, a regional agreement between Umeå University and Västerbotten County Council (ALF), the Norrbotten County Council, VISARE NORR fund: Northern County Council Regional Federation are acknowledged for financial suppor. 